\title{
Chronic Bacterial Laryngitis: A Diagnostic Pitfall for Clinicians
}

\author{
Hirokazu Toyoshima ${ }^{1}$, Hiroyuki Yamada ${ }^{2}$, Motoaki Tanigawa $^{3}$ and Shigetoshi Sakabe ${ }^{1}$ \\ Key words: chronic bacterial laryngitis, carcinoma, Staphylococcus aureus, polymicrobial infection, \\ sulfamethoxazole/trimethoprim
}

\author{
(Intern Med Advance Publication) \\ (DOI: 10.2169/internalmedicine.7796-21)
}



Picture 1.

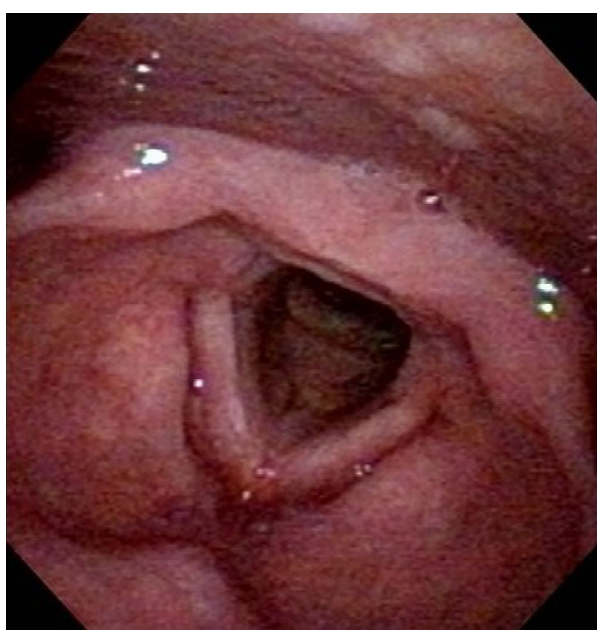

Picture 2.
A 72-year-old Japanese man presented with persistent hoarseness for 1 month. He was a former smoker (Brinkman Index 2000). Laryngoscopy revealed an edematous vocalcord without erythema and an irregular vocal-cord surface covered by a purulent scab (Picture 1). Bronchoscopy findings showed no evidence of endobronchial tuberculosis. A vocal-cord biopsy was negative for malignancy and $\mathrm{Myco-}$ bacteria but positive for methicillin-resistant Staphylococcus aureus, Streptococcus agalactiae, Moraxella catarrhalis, and Corynebacterium accolens. Based on the pathological and microbiological results, the patient was diagnosed with chronic bacterial laryngitis (CBL). He received two-week oral sulfamethoxazole/trimethoprim treatment based on the susceptibility test results and fully recovered, with resolution of the vocal-cord findings (Picture 2). A biopsy is required to diagnose such rare cases, as CBL may mimic carcinoma (1) and commonly occurs as a monomicrobial infec- tion. He was successfully treated with short-course antibiotic therapy, whereas $S$. aureus-associated CBL requires prolonged antibiotic treatment (2).

The authors state that they have no Conflict of Interest (COI).

\section{Acknowledgments}

We would like to thank Editage [http://www.editage.com] for editing and reviewing the English language content of this manuscript.

Authors' contributions: All authors participated in the treatment of this case, and the first author drafted the manuscript. All authors read and approved the final manuscript.

Consent for publication: Written informed consent was obtained from the patient for the publication of this case report and accompanying images. A copy of the written consent is available

\footnotetext{
${ }^{1}$ Department of Infectious Diseases, Japanese Red Cross Ise Hospital, Japan, ${ }^{2}$ Department of Otorhinolaryngology, Head and Neck Surgery, Japanese Red Cross Ise Hospital, Japan and ${ }^{3}$ Department of Respiratory Medicine, Japanese Red Cross Ise Hospital, Japan Received: April 19, 2021; Accepted: July 5, 2021; Advance Publication by J-STAGE: September 18, 2021 Correspondence to Dr. Hirokazu Toyoshima, hirokazutoyoshima@gmail.com
} 
for review by the Editor-in-Chief of this journal on request.

Ethical approval: This study was approved by the institutional review board and ethics committee of Japanese Red Cross Ise Hospital.

\section{References}

1. Zhukhovitskaya A, Verma SP. Identification and management of chronic laryngitis. Otolaryngol Clin North Am 52: 607-616, 2019.

2. Thomas CM, Jetté ME, Clary MS. Factors associated with infectious laryngitis: a retrospective review of 15 cases. Ann Otol Rhinol Laryngol 126: 388-395, 2017.

The Internal Medicine is an Open Access journal distributed under the Creative Commons Attribution-NonCommercial-NoDerivatives 4.0 International License. To view the details of this license, please visit (https://creativecommons.org/licenses/ by-nc-nd/4.0/).

\section{(C) The Japanese Society of Internal Medicine Intern Med Advance Publication}

